\title{
IFDMR Establishment - A Solution for Space Debris Mitigation and Removal
}

\author{
Abbas Sheer ${ }^{1}$, Shouping $\mathrm{Li}^{1}$, Fatima Sidra ${ }^{2}$ \\ ${ }^{1}$ School of Law, Beijing Institute of Technology, Beijing, China \\ ${ }^{2}$ School of Management, Virtual University Pakistan \\ Correspondence: Dean of School of Law, Beijing Institute of Technology, Beijing, China
}

Received: May 21, 2019

doi:10.11114/ijlpa.v2i1.4356

\author{
Accepted: June 27, $2019 \quad$ Online Published: June 27, 2019 \\ URL: https://doi.org/10.11114/ijlpa.v2i1.4356
}

\begin{abstract}
Space debris is a global mounting ultimatum to the enduring maintainability of outer space activities and ought to be managed from the very beginning; otherwise, it will be too late. Based on the last couple of years, collisions are incidents that have enhanced space debris accumulation, and the rate at which space activities have resulted in the production of debris is at a threshold position in a linear fashion. Ultimately, space has become the rendezvous of space debris. Based on the growing accumulation of debris and the emerging apprehension regarding a horrible strike and collapse of whole space programs, to remove debris is very expensive process so this paper focuses on the financial challenges and solution as well. Developing and developed countries realize the value of a competent establishment of an International Fund for Debris Mitigation and Removal (IFDMR) that could address the financial issues. Thus, this paper suggests to create incentive opportunities for remediation of space debris and penalties for its production. it would be very strong and effective mechanism to halt this mounting issue by utilizing international fund. The revenue for fund would be collected mainly from contributing member states space agencies, the proportionate contributors of debris producer like (US, RUSSIA, CHINA), and other relevant stack holders, insurance of missions, levying fee from every launching, donations from various international organizations and private entities and UN Aid etc. The fund would be operated by the Director of fund having board of directors as management team under the umbrella of UNOOSA.
\end{abstract}

Keywords: space debris mitigation \& remediation, International Fund for Debris Mitigation and Removal (IFDMR), sustainability of outer space

\section{Introduction}

Throughout the centuries, outer space and the moon have been a source of inspiration. The first satellite, SPUTNIK (Walter Sullivan 1957), and the moon walk of Neil Armstrong (JN Wilford, 1969) marked the dawn of space age. The development of science and technology has enabled the inspection, observation, and usage of outer space. The space race began during the cold war, and eventually, space development evolved. More than 50 years of space bustle caused by different space actors has resulted in leftover debris. This garbage is in the environment and an unending eternal hazard that makes the outer space environment vulnerable (Listner 2012). Empirical evidence has shown that traditional "fire and forget" and "big skies" mentalities have resulted in an accumulation of this debris at a threatening level.(Dunstan and Werb 2009) Although the risk associated with debris accumulation was identified early (Elmer H. Davison \&Paul C. Winslow 1961), the full extent of the hazards was not realized for several years (Donald J. Kessler \& Burton G. Cour- Palais 1978). Space-faring nations have only recently begun to heed the warnings of orbital debris proliferation (NASA 1995). It is now widely recognized that controlling debris production is crucial for maintaining space security and, in turn, international peace and security (Wright 2007). The (ILA) was forced to formulate the "International Instrument on the Protection of Environment from Damage Produced by the Space Debris,"(Bockstiegel 1995) and these instructions have also been conceded by the STSC of UNCOPUOS (Edward Finch 1995).

A decade ago, intended or coincidental in-orbit breaking-ups, striking, and flare-ups were observed. China's deliberated (ASAT) test and the very grave coincidental collision of a deactivated Russian satellite with a US functional satellite were two major episodes that resulted in the dirty fog of space debris (Weeden 2010). Currently, China's Tiangong-1 space station was knocked down toward the Earth, showering debris on the surface of the Pacific Ocean and massively enhancing the ash residue. The United States registered a record 308,984 probable space-junk hits 
in 2017, and the situation might become aggravated, which is very alarming for outer space, and the United States announced at least 655 "alarming-reportable" ultimatums from satellite operators (Mosher 2018). Thus, the rapid growth of space debris creates a threat to functional satellites, the ISS, and astronauts (J.C. Liou 2011). The catastrophic possibility of the smallest debris particle from comparative effective momentum in the orbits are giant and towering. The mean momentum of orbital debris compared with a space object will be almost $10 \mathrm{~km} / 1 \mathrm{sec}$. and this is equal to approximately ten times the speed of a bullet in the LEO. Resultantly, a hit from even a minuscule piece of debris will produce a substantial amount of energy (Liou 2012). The elevating mass of space debris may result in a girdle of debris encompassing the Earth that poses the risk of chain reaction (Donald J. Kessler \& Burton G. Cour- Palais 1978) and may begin to increase in an unmanageable manner because of a striking chain reaction. Ultimately, this phenomenon will enhance the chances of collision ten times and soon endanger all functional space vehicles if the space debris population remains increasing and steady. There is apprehension regarding debris hitting the Earth's atmosphere and then breaking up, creating a grave threat to the population(J.C Liou 2008). A supplementary "growth feature" that may furthermore effect space debris proliferation is reputed "macro-constellations" that will involve large numbers of petty satellites with a minor running lifetime and constrained steering aptitude (G. Wyler 2019) -(Jakhu, R., Pelton 2017) (IADC steering group 2017). currently, around 1000 energetic satellites in the Low Earth Orbit with the publicized One Web macro-constellation network and this figure will virtually twofold, (FCC Grants Oneweb 2017) additionally, if altogether three constellations on the list are propelled, it will produce a decupled escalation in the LEO satellite populace of debris and reveal that there is a deleterious situation.

\section{Who Will Provide Financial Support for Space Debris Removal}

\subsection{Establishment of International Fund for Debris Mitigation and Removal (IFDMR) to Meet the Cost for Removal of Space Debris}

Who will provide finance support for removal of space debris because it's very expensive practice and huge amount of money is required. It demands substantial expenses and latest technology still required to be expanded for Active debris removal. The panacea of these challenges. the establishment of an International Fund for Debris Mitigation Removal (IFDMR) for the withdrawal of space rubble and wreck that partly embraced from X-prize pattern, wherein all the space systems and launch machinists would share equally public and private according to their percentage to resent contribution of international launched, hustle and bustle etc. (Jakhu 2012) mainly the "future oriented" method to begin and having numerous probable interests. Another approach the "looking back" space faring nations are supposed to be accountable for creating or producing debris to spend a corresponding contribution of the expenditures for the sake of elimination of debris is fair, perhaps very least feasible. The idea of establishing an International Fund for Debris Mitigation and Removal (IFDMR) that creates fiscal motivations for a "clean launch" and for exclusion of defunct space objects at the completion of operation. Further it would create a mechanism for financing an active remediation process,

\subsection{The Prime Aim of International Fund for Debris Mitigation and Removal (IFDMR)}

The main purpose of global monetary fund is actually to aid: (I) for the mitigating the future build-up of debris; (II) for the space Debris alleviation would reimburse for removal service (UNCUPOS 2012) perpetually (to adjust expenses for alleviation of prevailing space debris plus spacecraft which vanish in the orbit) (III) the movement of doomed objects in GEO to the graveyard orbit. (IV) besides it would trigger a variety of "global licensed entities" to contend growing the required tech and recompense while having effective new advance technology for removing debris and the capable private entities would be hired for removing debris paid by this fund. Licensed entities supposed to be qualified for the removal of debris or burry it in the graveyard orbit would be needed to operate according to proper international rules, regulations and security criteria and who assume salvage operation would only be paid at the end of alleviation completion while the weight and size of removed debris record would be maintained properly. (V) To pay the hired entities for removal of UN-know debris which having no record to the UN Secretary General. (VI) To meet miscellaneous expenditures relating to space debris removal. An international bank (either numerous banks or may be any launching insurance entities/firms) would be appointed to manage the payment and investment of funds. Government administrations as nominated by the UNOOSA would execute funds collection as well as its deposition into the designated bank before launching.

The license would be issued to such kind of removal entities for executing operation by their own states by following the global instructions or (non-binding) guidelines regarding space debris remediation. Holger Krag, Head of ESA's Space Debris Office while chairing the session expressed his views about mitigations guidelines that,

"rapid and genuine executions of mitigation measures for all missions and a change in the operational pattern to consider space-object dispose of as substantial section of whole mission are indispensable to contain the germination of the space debris population and to safe and protect space for humanity," (Krag 2017.) Such mechanism would require to have 
modern and fresh global convention or protocol to reshape the existing Liability Convention. By and large, it is deduced that the "international economic fund" procedure could aid to make every right for inducement and encouragement: (i) to gift launching entities for a clean launch and establish a debris removal bonus with reward for accurate candidate taking off appropriate identified object exactly; (ii) to remunerate operators for casting off debris appropriately at completion ; (iii) the "sunset provision" would create a fixed aim to achieve goal completed ; (iv) this International Fund for Debris Mitigation and Removal (IFDMR) design or vision would bring interest the competition among the states not only for development but also cost effective new technology (Pelton 2012). Whereas the best and effective approach is a formation of Global economic fund to conduct debris removal and to involve the provision of open market bonuses to the licensed entities certified by UNOOSA. And there would be penalty for NOT alleviating space debris and there would be definitely attractive gifts/reward for developing advance method for salvaging from the Earth orbit, so such type of fund eventually international fund would be established by the space-faring nations aiming to confront the burning issue of debris. This becomes a dynamic "forward looking" innovative approach to handle the challenges instead only pursuing "looking back methodology" to confront debris matter with lack of fund procedure.

\subsection{Procedure for Establishing International Fund for Debris Mitigation and Removal}

International Fund are founded by the International treaty, or International agreement or by the soft law etc. same as International Convention on the Establishment of an International Fund for Compensation for Oil Pollution Damage ("1971 Fund Convention") by international convention, under the International Maritime Organization (IMO) proved a useful mechanism for ensuring the payment of compensation for oil pollution damage for safety and security (IOPC Fund 2016) under patronage of United Nations or may be outside the UN but it needs to be registered at the secretariat of UN in pursuance of article 102 of UN (UN Charter)- VCLT 1969). In order to establish as a preliminary procedure, there are two possible ways are following,

The First one step, it prerequisites to prepare a "Draft for Convention on the Establishment of International Fund for Debris Mitigation and Removal (IFDMR)" should be legislated by excellent space law professors, space scientists or diplomats in teamwork with professionals of the space-faring nations. The task should be assign to the Tech \& legal committee of UNCOPUOS which already has done a lot of work on it. They have been working for the guidance and legal suggestions to prepare a draft and it would be approving through dialogues, consensus and energetic discourse.

Second step, a simple resolution or declaration prepared by the international community or space faring nations should be put up before the UN General Assembly demanding the establishment of International Fund for Debris Mitigation and Removal (IFDMR) aiming space debris remediation and mitigation particularly can be solved by dialoged, discussion among the space faring nations for final approval of draft. So the researcher in this paper envisaged the establishment of International Fund for Debris Mitigation and Removal (IFDMR) by international agreement or even by the soft law for the security and safety of the outer space.

\subsection{Contribution towards International Fund for Debris Mitigation and Removal}

Currently, there is no any structure for funding space debris removal world widely. Economic solutions should be seriously considered. Realistically this may mean first establishing national or regional funding mechanisms and then let these "funds" evolve toward a global economic system. Considering the presumably high costs and risks associated with ADR, it is proposed that an international fund should be created undertaking orbital debris removal, and to meet the liabilities linked with debris. The necessity of establishing a debris removal fund was recognized by (STCS) Scientific and Technical Subcommittee of the COPUOS early in 1998 (UNCOPUOS 1998) but it was not carried forward officially. The creation of (IDREF) International Debris Removal Economic Fund is an important step in incentivizing govt. and non- govt. firms to expend in the field of research \& development of space debris removal technologies, by assuring them of the possibility of gaining revenues and clearing uncertainties associated with the liability issue. It could be used to cover, at least partially, the costs incurred in the course of ADR. If States can do it multilaterally it would significantly ease the concern over the dual-use nature of such activities. It could also be used to assist the indemnity, e.g., through commercial insurance, for possible damages caused in debris removal, thereby relieving potential operators from the concern that unsuccessful operations are to entail liabilities. A question may follow on how financial contributions are spread in the establishment of such fund. The sharing amount from the State ought to be depend upon either market-sharing responsibility for space debris into the orbit recently (Sundahl 2000) or the scale of power States have in space (Su 2016).Also every upcoming launching fee should be aided to the new established global economic fund (A.Williamson 2012). NASA proposed (Peter R de Sledding 1997) the ORION Project, which would bring into use the laser and earth sensors for re-entering the out of controlled of various-sized debris into the earth's atmosphere to effect harmless burn up. It is asserted by NASA that when there will be appropriate availability of funds then the system might be functional within couple of years. This is positive indication towards debris alleviation endeavors. 
There are different ways to raise fund, like almost space-faring nations have endorsed some insurance on the missions which are under their command and control, generally encompassing launch and on-orbit execution. About 0.86b USD with premium rates of $\approx 10 \%$ revenue was collected from the insurance premiums in 2011 and currently the global space economy totaled $\$ 383.5$ billion worldwide. (COLORADO SPRINGS 2017). It is obligatory for all the FAA-licensed launches from the US to buy launching and liability surety and it's a routine exercise in many other jurisdictions as well. About ninety percent of space insurance trade volume embrace transport network facilities of GEO, which are not noteworthy debris givers (FAA, 2010), so such insurance-based funding is very useful to regime.

1. About $5 \%$ an auxiliary 'debris surcharge insured worth might enhance the revenue around $50 \mathrm{~m} \mathrm{USD}$, considering the 2011 records annually by way of a sample. Then extreme insurance premium level possibly will be toped up at $20 \%$, to cover the expenditures of the companies entailing insurance. Where there is incapability for ADR of their satellite in the Missions then there would have the surcharge kept by debris elimination fund. While it will be reimbursed when the job done successfully by removing, placing or deorbiting into the graveyard orbit at the end of mission, thus the same suggestions proposed by Pelton. The debris surcharge should be taken as a 'cost of doing businesses. Such kind of design would definitely be useful for the mission operators by alleviating the debris which might smash with their belongings. Surcharge could boost up the operation designers to finance for developing advance and new technology for ADR, and Pelton revamped the design of "extended launch insurance (Pelton 2012)" According to idea to raise for each launching a supplemental or subsidiary surety sharing according to the proportion of the gross task consumption expenses for the debris remediation.

All stakeholders who are included in the space development and enjoying advantages either directly or indirectly should cooperate accordingly or contribute fair funding for the exclusion undertakings for Debris. Furthermore, it is also anticipated that all interested party's including's, launching operators, Space systems possessor or holder and operatives if public or private should offer financial support for the augmentation of Fund on an equitable basis and as well as donation from such entities like enterprisers and international organizations voluntarily for the safety and security of space activities.

Just only Insurance-based funding is inadequate to meet the expenditures of the ADR and mitigation efforts, so there is need of some extra funding designs.

2- It is proposed to impose space tax, by getting fees from the states at every launching etc. and there can be many resources which could generate revenue for sustainability of space additionally. Assume that usage of space would be adjoined to all space relevant Final-User amenities. The Futron Corporation's State of the Satellite Industry Record calculates the 2010 earning from the Satellite Services, for instance, (mobile voice and data, consumer, and remote sensing) to be $90.89 \mathrm{~m}$ USD.(Futron Corporation 2011).

3- It is suggested that the Subscription of governments should make an agreement to acquire services for removal of space debris produced by themselves during public space exertions (1\%/annum) on a commercial basis. Every subscribing state be permitted for imposition of public" space waste scrap or space garbage" collection tax on final users prevails in the country (UNCUPOS 2012). Almost the capital would be generated from the member agencies and nation states annually, insurance debris levy, entities as private donors, enterprisers and international organizations as well for the global fund.

4- it is envisaged from the current figure that the possession of maximum space objects in numbering of space objects, size of objects and as well as space programs almost belongs to the three 'big players' Russia, China and the U.S (David Wright,). Keeping in view above figure (Samantha Lee 2018). 


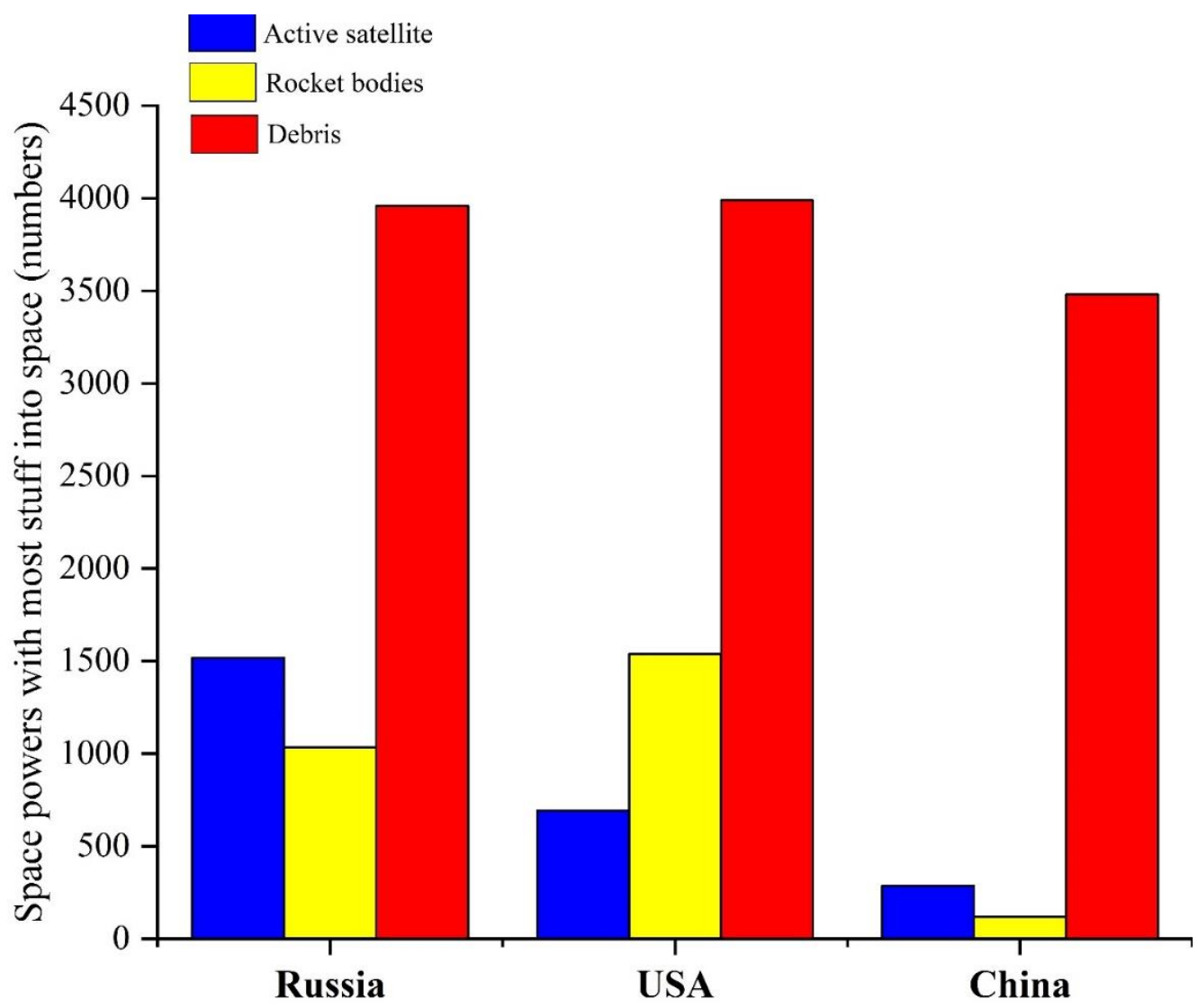

Figure 1. Contribution of Russia, China and the U.S in space debris

It is suggested that above mentioned space powers should undertake special proportion of obligation in case of funding as well as developing ADR plans according to their share. No doubt, that maximum countries including developed and developing would be benefited by debris removal process and they having maximum share in production of space debris at outer space, as customary rule which implements under the general international law, who has adulterated would compensate for the tidy-up costs is mandatory (Porras, Alleana 1992).

\subsection{Sketch for Expecting the International Fund for Debris Mitigation and Removal}

The Professor Joseph N. Pelton discoursed global economic fund covering global debris eradication endeavors would be designed as an IFDMR for orbital debris at ISU symposium in 2012, under the umbrella of UNOOSA. Whereas the fund would be run by a board of directors, formed, and funded by the member's state agencies while representing all the consumers for strategic, commercial, govt. and also for research and educational perspectives. The collected revenue would be enough for dispersing the fund for the sake of some special tasks like space debris mitigation and remediation advance technologies, research and development, debris monitoring, While the fund will be managed by the board of directors and management board and the board will take decisions about which area of Orbit Debris Mitigation attempts should be funding annually in accordance with the demand. It is envisaged very powerful and strong autonomous, International Fund for Debris Mitigation and Removal (IFDMR) for the safety and security and long term sustainability of outer space to have following body structure of new International Fund for Debris Mitigation and Removal, 


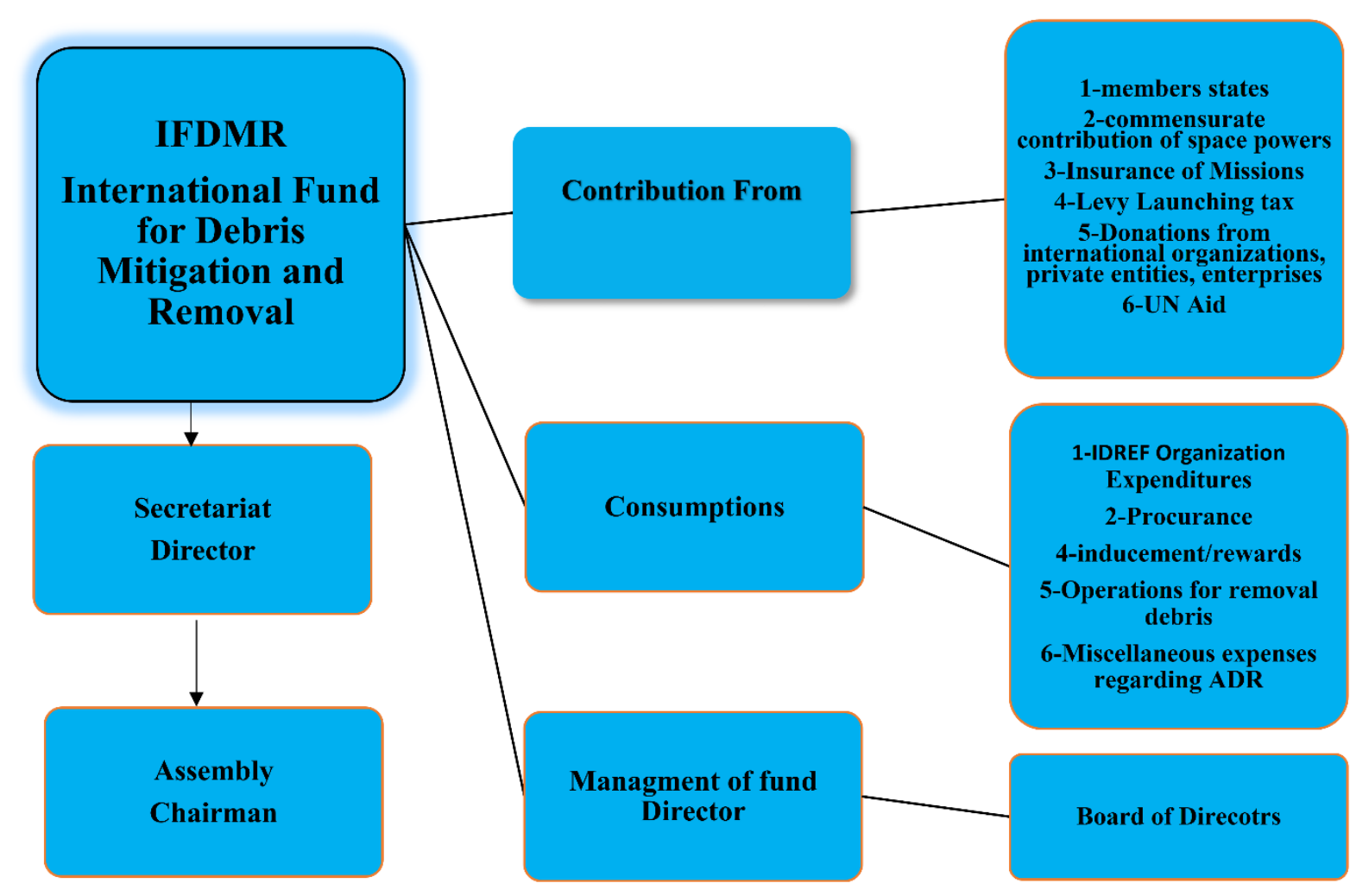

Figure 2. International Fund for Debris Mitigation and Removal

\section{1-Assembly}

The International Fund for Debris Mitigation and Removal is proposed to have an Assembly composed of all Member States/ space agencies and an Executive Committee shall consist of one third of members elected by the Assembly. The Assembly will be the supreme governing body of the organization having, inter alia, the responsibility for financial matters.

\section{2-Secretariat}

The International Fund for Debris Mitigation and Removal (IFDMR) is proposed to have a Secretariat, based anywhere suitable headed by a Director. The Fund Secretariat will also have supposed to administers the global Economic Fund. Key management personnel will have supposed to involve the Director, Deputy Director / Head of the Finance and Administration Department, the Head of the External Relations and Conference Department, the Head of the Claims Department, and the Legal Counsel. The Director of the Fund will be assisted by a Management Team. The Fund use external consultants to provide advice on legal and technical matters as well as on matters relating to management. The main administrative and decision making body is the secretariat is proposed to composed of 13 members, and the distribution according to the following methods; 3 of them are super power of space, and 3 from the biggest consumers and largest investor made preparations for the business activities in outer space; 5 from developing countries; the rest is to achieve a fair allocation of seats. To choose unanimous consent should be the fundamental mechanism for the council to vote, when no consensus is reached, then a majority of not less than $2 / 3^{\text {rd }}$ members of secretariat the shall pass decision.

\section{3- Audit Body}

The governing bodies of the new Global Economic Fund will have supposed to have established a joint Audit Body for the Funds composed of five members elected by the Assembly: one named Chairman nominated by Fund Member States, three named individuals nominated by Fund Member States and one external expert with experience in audit matters nominated by the Chairman of the Assembly.

\section{4-Financial risk management}

The Funds' risk register will have five areas to identify which are finance/contributions, governance/management, compensation, safety/security, and communications/ publications. The sub-risks, the process and procedures for 
management of these risks have been mapped, assessed and documented. This exercise allows the Funds priorities the key risks and to ensure that these risks have been adequately mitigated and managed. Annual reviews will be conducted of the Funds' risk register by the management and of the Key Risk Register by the Audit Body. The Fund will have established a framework of internal control.

5-Expenses

IDREF Fund Expenditures, inducement/rewards, Operations for removal debris and Miscellaneous expenses regarding ADR everything will be meet through this Fund.

\section{Conclusion}

It would be miserable to wait for a catastrophic incident and then remain unsuccessful to counter this grave concern in a meaningful and practical manner. The dilemma is that space debris creation is unavoidable but could be alleviated such that the damage could be minimized. Although the dilemma before us that space debris-creation is unavoidable yet alleviated thoroughly but it can only be minimizing. Huge money is needed for removing debris because it's very expensive process, so in order to meet expenses this paper proposes to establish an (IFDMR) to address the financial issues aiming Debris remediation so that expenses could be meet during the debris removal operations compensate the and other relevant expenditures. It is envisaged to attract them by provisions of rewards to those entities who are removing debris diligently by utilizing international fund and also director of fund can hire any private capable firm for removing debris. It is suggested to hold convention which permits the right awards for clean maneuvering and punish for not cleaning at the end of mission would definitely prove an effective and result-oriented tool. This idea of rewards will bring revolution in the technology innovations to halt the rising issue of space debris. The revenue for fund would be collected mainly from contributing member states space agencies, the proportionate contributors of debris producer would share bulk amount of funding rightly, and other relevant stack holders as well. Furthermore, plenty of avenues for collecting like through the insurance of missions, levying fee from every launching and donations.

\section{References}

A.Williamson, R. (2012). Assuring the Sustainability of Space Activities. Space Policy 28(3), 154-160. https://doi.org/10.1016/j.spacepol.2012.06.010

Bockstiegel, K. (1995). The Draft of the International Association for a Convention on Space Debris.

Colorado, S. C. (2017). Space Foundation Report Reveals Global Space Economy at \$383.5 Billion in 2017. https://www.spacefoundation.org/news/space-foundation-report-reveals-global-space-economy-3835-billion-2017

David, W. (2012). Where Did All That Space Debris Come From? Scientic Magzine.

Donald, J. K., \& Burton, G. C. P. (1978). Collision Frequency of Artificial Satellites, 83(A6), 2637-2646. https://doi.org/10.1029/JA083iA06p02637

Dunstan, J. E., \& Bob, W. (2009). Legal and Economic Implications of Orbital Debris Removal : A Free Market Problem. Int. Conf. on Orbital Debris Removal. http://www.scribd.com/doc/23379988/Legal-and-Economics-Implications-Of-Orbital-Debris-Removal

Edward, F. (1995). No TitleHeavenly Junk III- Space Debris. In 38 Proc. on L. Outer Space 102 (1995) 46th International Astronautical Congress International Institute of Space Law International Aeronautical Federation 38th International Colloquium on the Law of Outer Space Oslo, Norway. Oslo,Norway.

Eichler, P., \& Rex, D. (1990). No TitleDebris Chain Reactions:Orbital Debris Conference: Technical Issues and Future Directions, In Debris Chain Reactions:Orbital Debris Conference: Technical Issues and Future Directions, AIAA/NASA/DOD. https://doi.org/10.2514/6.1990-1365

Elmer, H. D., \& Paul, C. W. Jr. (1961). Space Debris Hazard Evaluation. https://ntrs.nasa.gov/archive/nasa/casi.ntrs.nasa.gov/19980228158.pdf.

FCC. (2017). Fcc Grants Oneweb Access To U.S. Market for Its Proposed New Broadband Satellite Constellation, no. 202. https://apps.fcc.gov/edocs_public/attachmatch/DOC-345467A1.pdf

Fund Convention. (1971). no. November 1969.

Futron, C. (2011). State of the Satellite Industry Report, no. August: 26.

Holger, K. (2017). The Inter-Agency Space Debris Coordination Committee ( IADC ) - An Overview of the IADC Annual Activities Overview of IADC - IADC Is an International Forum of National and International, no. February.

IADC steering group. (2017). IADC Statement on Large Constellations of Satellites in Low Earth Orbit. 
https://www.iadc-online.org/Documents/IADC Statement on Large Constellations rev 3.pdf

IOPC Fund. (2016). International Oil Pollution Compensation Funds - Annual Report. https://doi.org/10.1016/S0143-7127(83)80005-2

Jakhu, R. (2012). Active Debris Removal - An Essential Mechanism for Ensuring the Safety and Active Debris Removal - An Essential Mechanism for Ensuring the Safety and Sustainability of Outer Space. 12, 50395. https://doi.org/10.1057/978-1-349-95121-5_2678-1

Jakhu, R., \& Pelton, J. (2017). In Global Space Governance. Cham, Switzerland: Springer. https://doi.org/ISBN978-3-319-54364-2.

Liou, J. (2012). Orbital Debris Modeling, 15 (March). https://doi.org/10.17226/4765

Liou, J. C. (2011). A Note on Active Debris Removal.15 Orbital Debris Quarterly News 7.

Liou, J. C., \& Johnson, N. L. (2008). Instability of the Present LEO Satellite Populations, https://doi.org/10.1016/j.asr.2007.04.081

Listner, M. (2012). Legal Issues Surrounding Space Debris Remediation. The Space Review.

Mosher, D. (2018). China's Tiangong-1 Space Station Knocked down towards the Earth. Business Insider, 2018.

NASA. (1995). Orbital Debris Mitigation Standard Practices, NASA Orbital Debris Program Office. http://www.hsdl.org.

of Comercial Space Transportation, Federal Aviation Administration's Office. 2010. "The Economic Impact of Comercial Space Transprotation on the U.S. Economy in 2009, no. September.

Pelton, J. N. (2012). Global Economic Fund for Space Debrs Remediation. In . Strasburg.

Peter, R. de S. (1997). Experts Take Steps to Solve Debris Problem, Space News, 3, 24-30.

Porras, A. M. (1992). The Rio Declaration Principle 16, A New Basis for International Co-operation. Review of European, Comparative \& International Environmental Law. https://doi.org/10.1111/j.1467-9388.1992.tb00043.x

Samantha, L. (2018). Countries with Most Stuff in Space and What It Is. Business Insider, 2018.

Su, J. Y. (2016). Active Debris Removal: Potential Legal Barriers and Possible Ways Forward.” Journal of East Asia and International Law, 9(2), 403-426. https://doi.org/10.14330/jeail.2016.9.2.05

Sundahl, M. J. (2000). Unidentified Orbital Debris the Case for a Market-Share Liability Regime. Hastings International and Comparative Law Review, 24, 125. https://doi.org/10.1016/1054-3139(95)80070-0

UN. n.d. Charter of the United Nations Chapter XVI — Miscellaneous Provisions Article 102.

UNCOPUOS. (1998). No Title." http://www.unoosa.org/pdf/reports/ ac105/AC105_697E.pdf.

UNCUPOS. (2012). Active Debris Removal - An Essential Mechanism for Ensuring the Safety and Active Debris Removal - An Essential Mechanism for Ensuring the Safety and Sustainability of Outer Space, 12, 50395 (January), 1-50. https://doi.org/10.1057/978-1-349-95121-5_2678-1

Vienna Convention on the Law of Treaties VCLT. (1969). no. May: 1447-65.

Walter, S. (1957). Navy Picks up Radio Signals. The New York Times, 1957. https://archive.nytimes.com/www.nytimes.com/partners/aol/special/sputnik/sput-02.html

Weeden, B. (2010). 2007 Chinese Anti-Satellite Test Fact Sheet. Swfound, 5-7. https://doi.org/10.1136/gutjnl-2015-310519

Wilford, J. N. (1969). We Reach the Moon.

Wright, D. (2007). Orbital Debris Produced by Kinetic-Energy Anti-Satellite Weapons. Celebrating the Space Age, 50 Years of Space Technology, 40 Years of the Outer Space Treaty, no. April: 155-64.

Wyler, G. (2019). Note from Chairman of OneWeb. 2019. http://www.oneweb.world/

\section{Copyrights}

Copyright for this article is retained by the author(s), with first publication rights granted to the journal.

This is an open-access article distributed under the terms and conditions of the Creative Commons Attribution License which permits unrestricted use, distribution, and reproduction in any medium, provided the original work is properly cited. 